\title{
COMPONENTES DE RENDIMENTO E PRODUTIVIDADE DE CULTIVARES DE TRIGO SUBMETIDAS AO PARCELAMENTO OU NÃO DE NITROGÊNIO
}

\author{
Vanderson Vieira Batista ${ }^{1}$; Matheus Cesar Salapataㄹ; Karine Fuschter Oligini ${ }^{1}$; Douglas Camana ${ }^{3}$; \\ Amanda Cassu da Fonseca ${ }^{3}$; Paulo Fernando Adami ${ }^{3}$ \\ ${ }^{1}$ Universidade Tecnológica Federal do Paraná. Via do Conhecimento, Km 01 - Fraron, Pato Branco - PR, Brasil, CEP 85503-390. \\ ${ }^{2}$ Agrocete - GRAP, Rua Anna Scremin, 800 - Distrito Industrial, Ponta Grossa - PR, Brasil. \\ ${ }^{3}$ Universidade Tecnológica Federal do Paraná, Estrada para Boa Esperança, Km 04 - Zona Rural, Dois Vizinhos-PR, Brasil, CEP \\ 85660-000 \\ *Autor para correspondência: Vanderson Vieira Batista, vandersonvbatista@hotmai.com
}

\begin{abstract}
RESUMO: O trigo é a espécie com maior potencial de uso no período de inverno e estudos sobre a produtividade dos genótipos e forma de utilização do nitrogênio $(\mathrm{N})$ na cultura, demonstram elevada importância. O estudo tem o objetivo de avaliar os componentes de rendimento e a produtividade de diferentes cultivares de trigo, submetidas a aplicação de $\mathrm{N}$ parcelado ou em dose única. $\mathrm{O}$ experimento foi conduzido no município de Realeza - Paraná, em delineamento de blocos ao acaso, com três repetições. Avaliou-se diferentes cultivares (Toruk, Sonic, Sossego e Sintonia) e duas formas de aplicação de N (parcelado e dose única). Mensurou-se o número de espiguetas e grãos por espiga, comprimento da espiga, produtividade e pH dos tratamentos. O comprimento da espiga é maior para a cultivar Sossego $(8,87 \mathrm{~cm})$ e menor para a cultivar Sintonia $(7,63 \mathrm{~cm})$. Sonic, juntamente com Sossego e Sintonia exibiram maior número de espiguetas por espiga e Sossego e Sonic maior número de grãos por espiga, quando o $\mathrm{N}$ foi aplicado parcelado. $\mathrm{O} \mathrm{pH}$ do trigo é maior na cultivar Toruk (81) em relação as demais cultivares, quando o $\mathrm{N}$ é aplicado parcelado. Sonic apresenta menor $\mathrm{pH}$ entre as cultivares quando a adubação é realizada em dose única. Sintonia e Toruk apresentam aumento de produtividade de 243 e $665 \mathrm{~kg} \mathrm{ha}^{-1}$, quando o $\mathrm{N}$ é aplicado em dose única. Entre as cultivares, Sossego, seguida de Toruk, Sintonia e Sonic proporcionaram maior produtividade respectivamente, independente da forma de aplicação de N. De modo geral, ocorreu uma variabilidade na resposta da produtividade e qualidade dos grãos de trigo em relação a cultivar e o modo de suprimento de $\mathrm{N}$, devido às diferenças de demanda nutricional das cultivares, no entanto, fica evidente que o fornecimento de $\mathrm{N}$ é essencial na triticultura, principalmente em períodos que antecedem a maior demanda nutricional, levando os materiais genéticos mais próximos a atingir o máximo potencial produtivo.
\end{abstract}

PALAVRAS-CHAVE: Adubação nitrogenada; Espiguetas; Perfilhamento; Triticum aestivum L.

\section{PERFORMANCE AND YIELD COMPONENTS OF WHEAT CULTIVARS SUBMITTED TO NITROGEN MANAGEMENT}

\begin{abstract}
Wheat is the most important used specie at winter and studies about cultivars performance and nitrogen management $(\mathrm{N})$ in new cultivar are of high importance. The objective of this study was to evaluate the yield and yield components of different wheat cultivars, submitted to the application of $\mathrm{N}$, in a single dose. The experiment was carried out in the city of Realeza - Paraná, in a randomized block design, with three replications. Different cultivars (Toruk, Sonic, Sossego and Sintonia) and two forms of $\mathrm{N}$ application (split and single dose) were evaluated. The number of spikelets and grains per spike, spike length, yield and $\mathrm{pH}$ of the treatments were measured. The spike length is higher for the Sossego cultivar $(8.87 \mathrm{~cm})$ and smaller for the cultivar Sintonia $(7.63 \mathrm{~cm})$. Sonic along with sossego and Sintonia exhibited higher number of spikelets per spike and Sossego and Sonic greater number of grains per spike when $\mathrm{N}$ was splitted at two applications. The $\mathrm{pH}$ of the wheat was higher for the cultivar Toruk (81) in relation to the other cultivars, when N was splitted at two applications. Sonic presents lower $\mathrm{pH}$ between the cultivars when the fertilization is carried out in a single dose. Sintonia and Toruk present a grain yield increase of 243 and $665 \mathrm{~kg} \mathrm{ha}^{-1}$, when N is applied in a single dose. Among the cultivars, Sossego, followed by Toruk, Sintonia and Sonic provided higher yield respectively, regardless of the application form of $\mathrm{N}$. In general, there was a variability in the response of productivity and quality of wheat grains in relation to cultivar and the mode of supply of $\mathrm{N}$, due to differences in nutritional demand of the cultivars, however, it is evident that the supply of $\mathrm{N}$ is essential in triticulture, mainly in periods that precede the greatest nutritional demand, taking the genetic materials closest to reaching the maximum productive potential.
\end{abstract}

KEYWORDS: Nitrogen fertilization; Spikelets; tillering; Triticum aestivum L. 


\section{INTRODUÇÃO}

O trigo (Triticum aestivum L.) é um dos cereais mais cultivados no mundo. O Brasil atingiu uma produção de $4.263,5$ e 5.239,0 mil toneladas de trigo na safra 2017 e 2018, sendo o estado do Paraná o maior produtor nacional (Conab, 2018). A cadeia produtiva do trigo é muito importante para o Brasil, pois gera milhares de empregos no país, em diversos setores (Rodrigues et al., 2014), por este motivo são imprescindíveis investimentos agronômicos que elevem sua qualidade e garantam a competitividade no mercado.

A eficiência produtiva do trigo é estabelecida prioritariamente em função da cultivar empregada, do ambiente, da adubação e das demais técnicas de manejo (Mazzoncini et al., 2015). Para Silva et al. (2012), os quais avaliaram a adaptabilidade e a estabilidade de distintas cultivares de trigo em diferentes épocas de semeadura no estado do Paraná, existe grande variação nos componentes de rendimento e na produtividade do cereal em função destes fatores, sendo importante identificar o genótipo que melhor se enquadra nas características de cada região, para então ser cultivado no local. Ainda, Silva et al. (2015), observaram que os componentes de produtividade do trigo podem apresentar variabilidade, em função do material utilizado, justificando ensaios regionais com as diferentes cultivares de trigo disponíveis.

Além da escolha de cultivares o nitrogênio apresenta grande capacidade de interferir, tanto de forma qualitativa como quantitativa, sobre a produtividade de grãos de trigo, evidenciando a importância do mineral para a cultura, uma vez que, o nitrogênio é um dos elementos chaves para a formação de inúmeros compostos essenciais nos grãos, como a formação de proteínas, glúten e carboidratos, sendo as proteínas responsáveis pela estabilidade, força de glúten e $\mathrm{PH}$ (peso do hectolitro), se tornando extremamente requerido pelas plantas de trigo (Cavalcante et. al., 2016). Ainda, os componentes de rendimento do trigo podem se beneficiar com a disponibilidade de doses maiores de nitrogênio (Zagonel et al., 2002), por ele ser constituinte das biomoléculas ATP, NADH e NADPH (Orso et al., 2014).

Diante da importância que o nitrogênio apresenta para o sucesso da produtividade do trigo, os produtores rurais utilizam fertilizantes nitrogenados na cultura. No entanto, a maioria dos produtores fornece o nutriente em cobertura e em dose única, fato este que pode propiciar a perda do nutriente no ambiente, pois sua dinâmica no solo é complexa (Prando et al., 2013). A maioria dos fertilizantes nitrogenados são altamente solúveis em água e com alta mobilidade, podendo ser facilmente perdidos por lixiviação e/ou volatilização no ambiente, o que diminui a eficiência de utilização nos cereais (Fan et al., 2004), principalmente em solos com baixo teor de matéria orgânica (Adam; Alvarez, 2015; Cavalcante et al., 2016). Neste sentido, supõese que as plantas não consigam absorver todo o nutriente fornecido em uma única dose, por conta de fatores bióticos e abióticos.

Por outro lado, imagina-se que ao realizar a aplicação parcelada de nitrogênio, a planta consiga absorver por um período maior de tempo o nutriente, expressando assim, o máximo potencial de produtividade do genótipo. Estudos conduzidos por Martins et al. (2014), demonstram que o parcelamento da adubação nitrogenada, aumenta a produtividade de grãos da cultura do milho. Já para a cultura do trigo, o parcelamento do nitrogênio está diretamente correlacionado com número de afilhos por planta, os quais demandam maiores quantidades do nutriente para o seu completo desenvolvimento, contribuindo consequentemente para elevar o rendimento de grãos (Camponogara et al., 2016). No entanto ressalta-se, que o parcelamento do nitrogênio resulta em maior custo de produção para o produtor.

Destaca-se, que são encontrados estudos na literatura relatando que não se tem ganhos produtivos com o parcelamento do nitrogênio na cultura do trigo (Pottker et al., 1984; Coelho et al., 1998; Silva et al., 2008). Porém, a maioria destes estudos são antigos, com mais de 10 anos, e durante este período ocorreu uma grande transformação na agricultura brasileira, principalmente com surgimento de novas cultivares de trigo, as quais possuem diferentes demandas nutricionais, o que dificulta uma única recomendação pontual, fato este que respalda novas pesquisas com o tema.

Sabendo da importância que o trigo representa para a economia, levando em consideração a diferença de estabilidade e adaptabilidade das cultivares encontradas atualmente no mercado e da dúvida entre parcelar ou não o nitrogênio na cultura, o estudo tem o objetivo de avaliar os componentes de rendimento e a produtividade de diferentes cultivares de trigo, submetidas a aplicação de nitrogênio parcelado ou em dose única.

\section{MATERIAL E MÉTODOS}

O experimento foi conduzido no município de Realeza - PR ( $25^{\circ} 36^{\prime} 41^{\prime}$ ' de latitude S e longitude de $53^{\circ} 33^{\prime} 26^{\prime \prime} \mathrm{W}$ ) com altitude de 420 metros. O solo é classificado como Latossolo Vermelho distroférrico (Bhering et al., 2008), com clima Cfa (subtropical úmido) sem estação seca definida (Alvares et al., 2013) e precipitação média anual entre 1.800 a 2.200 $\mathrm{mm}$ ano (lapar, 2018). 
Utilizou-se delineamento de blocos ao acaso, com parcelas subdivididas e três repetições. $\mathrm{Na}$ parcela principal foi inserida as cultivares de trigo (Toruk, Sonic, Sossego e Sintonia) e na subparcela as formas de aplicação de nitrogênio (parcelado e dose única). Cada bloco foi composto por três parcelas experimentais (PE) de 2,4 m de largura (15 linhas de semeadura de trigo) por $20 \mathrm{~m}$ de comprimento. Cada $P E$ foi dividida em duas unidades experimentais $(2,4 \times 10 \mathrm{~m})$ para implantação do fator B. Já as unidades de observação (UO) foram compostas pelas cinco linhas centrais de cada unidade experimental, por cinco metros de comprimento cada $\left(4 \mathrm{~m}^{2}\right)$.

As cultivares avaliadas apresentam elevada capacidade produtiva, com ciclo superprecoce (Sonic), precoce (Sintonia) e médio (Sossego e Toruk) (Biotrigo, 2018). A cultivar Sossego é classificada como trigo pão, Sonic e Sintonia como trigo melhorador e Toruk como dupla afinidade (pão/melhorador) (Biotrigo, 2018).

O experimento foi implantado em 06 de maio de 2017, utilizando uma semeadora de arraste com 15 linhas e espaçamento entre linhas de $16 \mathrm{~cm}$. Foi utilizado densidade de semeadura de 60 sementes por metro linear, profundidade de deposição de sementes de dois $\mathrm{cm}$ e no sulco de semeadura adicionou-se $300 \mathrm{~kg} \mathrm{ha}^{-1}$ de adubo químico com formulação 8-20-20 (N-P $\left.\mathrm{O}_{5}-\mathrm{K}_{2} \mathrm{O}\right)$.

$A$ aplicação de nitrogênio $(\mathrm{N})$ (fator $\mathrm{B}$ ) ocorreu quando as plantas se encontravam no estádio fenológico de duplo anel (início do perfilhamento), sendo aplicado $120 \mathrm{~kg} \mathrm{ha}^{-1}$ de $\mathrm{N}$ nas PE com dose única e $60 \mathrm{~kg} \mathrm{ha}^{-1}$ de $\mathrm{N}$ nas $\mathrm{PE}$ com parcelamento de $\mathrm{N}$. A segunda aplicação de $\mathrm{N}\left(60 \mathrm{~kg} \mathrm{ha}^{-1}\right)$ para o tratamento parcelado, foi realizada no pleno perfilhamento.

O manejo de plantas daninhas ocorreu primeiramente antes da semeadura utilizando os herbicidas com o princípio ativo glifosato potássico $\left(620 \mathrm{~g} \mathrm{~L}^{-1}-(62 \% \mathrm{~m} / \mathrm{v}) 2 \mathrm{~L} \mathrm{ha}^{-1}\right)+$ sal de dimetilamina do ácido 2,4 - diclorofenoxiacético (2,4 - D Amina) (806 g L-1 $\left.(80,6 \% \mathrm{~m} / \mathrm{v}) 0,75 \mathrm{~L} \mathrm{ha}^{-1}\right)$ e 25 dias após a emergência utilizando o metsulfurom-metílico $(600 \mathrm{~g}$ $\left.\mathrm{kg}^{-1}(60 \% \mathrm{~m} / \mathrm{m}) 4 \mathrm{~g} \mathrm{ha}^{-1}\right)$.

Também, aplicou-se redutor de crescimento entre o primeiro nó perceptível e o segundo nó visível, com produto comercial composto por trinexapaque-etílico $\left(250 \mathrm{~g} \mathrm{~L}^{-1}(25 \% \mathrm{~m} / \mathrm{v})\right)$ na dose de $0,5 \mathrm{~L} \mathrm{ha}^{-1}$.

Já o manejo de pragas foi realizado conforme avaliação de níveis de infestação na cultura. Ocorreu uma alta infestação de lagartas no início de desenvolvimento da cultura, sendo utilizado metomil (216 $\left.\mathrm{g} \mathrm{L}^{-1}(21,6 \% \mathrm{~m} / \mathrm{v}) 1 \mathrm{~L} \mathrm{ha}^{-1}\right)$ para o controle destas. Também se aplicou tiametoxam $\left(141 \mathrm{~g} \mathrm{~L}^{-1}\right.$ $(14,1 \% \mathrm{~m} / \mathrm{v})+$ lambda-cialotrina $\left(106 \mathrm{~g} \mathrm{~L}^{-1}(10,6 \%\right.$ $\mathrm{m} / \mathrm{v}) 0,15 \mathrm{~L} \mathrm{ha}^{-1}$ ) para o controle de pulgões.

Para manejo de doenças utilizou-se propiconazol $\left(250 \mathrm{~g} \mathrm{~L}^{-1}(25 \% \mathrm{~m} / \mathrm{v}), 0,5 \mathrm{~L} \mathrm{ha}^{-1}\right)$ no início de desenvolvimento das plantas. Também, um segundo controle foi realizado com propiconazol, $(0,5$ L ha $\left.{ }^{-1}\right)$ + azoxistrobina $\left(200 \mathrm{~g} \mathrm{~L}^{-1}(20 \% \mathrm{~m} / \mathrm{v})+\right.$ ciproconazol $\left(80 \mathrm{~g} \mathrm{~L}^{-1}(8 \% \mathrm{~m} / \mathrm{v}) 0,3 \mathrm{~L} \mathrm{ha}^{-1}\right)$ e o terceiro controle com princípio ativo de azoxistrobina $(200 \mathrm{~g}$ $\left.\mathrm{L}^{-1}(20 \% \mathrm{~m} / \mathrm{v})\right)+$ ciproconazol $80 \mathrm{~g} \mathrm{~L}^{-1}(8 \% \mathrm{~m} / \mathrm{v}) \mathrm{com}$ dose de $0,3 \mathrm{~L} \mathrm{ha}^{-1}$ + propiconazol $\left(250 \mathrm{~g} \mathrm{~L}^{-1}(25 \%\right.$ $\left.\mathrm{m} / \mathrm{v}), 0,5 \mathrm{~L} \mathrm{ha}^{-1}\right)$. Juntamente com o primeiro e segundo manejo de doenças fúngicas, aplicou-se fertilizante foliar a base de cobre e boro $\left(0,2 \mathrm{~L} \mathrm{ha}^{-1}\right)$.

Todas as aplicações de produtos fitossanitários foram realizadas com um pulverizador acoplado a um trator, com vazão de $165 \mathrm{~L} \mathrm{ha}^{-1}$.

O ponto de colheita foi observado em 26 de agosto de 2017 para a cultivar Sonic e para as demais cultivares no dia 2 de setembro de 2017. No ponto de colheita das cultivares, avaliou-se o número de espiguetas em 10 espigas por UO. Também, foram determinados em 10 espigas por UO o comprimento da espiga $(\mathrm{cm})$ e o número de grãos por espiga, sendo considerado para a análise de dados o valor médio observado na amostragem.

A colheita foi feita de forma manual. Após a colheita foi realizada a trilha com um batedor de cereais da Universidade Tecnológica Federal do Paraná, campus Pato Branco, e determinada a umidade pelo método da estufa a $105 \pm 3^{\circ} \mathrm{C}$, por 24 horas (Brasil, 1992), e os resultados obtidos em porcentagem de teor água, em base úmida. Com base na umidade, estipulou-se a produtividade de grãos da UO com umidade de $13 \%$, sendo o valor extrapolado para $\mathrm{kg} \mathrm{ha}^{-1}$. O peso hectolitro $(\mathrm{PH})$ dos grãos foi determinado com utilização de balança modelo Dalle Molle, seguindo a metodologia descrita nas Regras de Análise de Sementes (Brasil, 1992), sendo os resultados expressos em $\mathrm{kg} \mathrm{hL}^{-1}$.

Os dados foram submetidos a análise de variância $(p<0,05)$ e havendo efeito significativo aplicou-se teste de comparação de médias (Tukey a $5 \%$ de probabilidade) com auxílio do programa estatístico Genes (Cruz, 2016).

\section{RESULTADOS E DISCUSSÃO}

$\mathrm{Na}$ Tabela 1 é apresentado um resumo da análise de variância (ANOVA), no qual é constatado interação entre os fatores avaliados para as variáveis número de espiguetas, número de grãos por espigas, $\mathrm{PH}$ e produtividade de grãos. Também, é constatado efeito significativo da cultivar sobre o comprimento da espiga de trigo. 
Tabela 1. Análise de variância para comprimento da espiga, número de espiguetas, número de grãos por espigas, peso hectolitro e produtividade em função de cultivares de trigo e parcelamento de nitrogênio, Universidade Tecnológica Federal do Paraná - UTFPR, 2019.

\begin{tabular}{|c|c|c|c|c|c|c|}
\hline \multirow{2}{*}{$\begin{array}{c}\text { Fatores } \\
\text { Avaliados }\end{array}$} & \multirow{2}{*}{ GL } & \multicolumn{5}{|c|}{ Quadrado médio } \\
\hline & & CE $(\mathrm{cm})$ & $\mathrm{NE}(\mathrm{cm})$ & NGE & $\mathrm{PH}$ & PROD $\left(\mathrm{kg} \mathrm{ha}^{-1}\right)$ \\
\hline Bloco & 2 & $0,065^{\mathrm{ns}}$ & $0,251^{\text {ns }}$ & $2,037917^{\text {ns }}$ & $0,000^{\text {ns }}$ & $208,005^{\text {ns }}$ \\
\hline Cultivar (C) & 3 & 1,560 * & $3,506^{* *}$ & $24,240^{\star *}$ & 15,000 ** & $7.191 .909,055^{* *}$ \\
\hline Resíduo & 6 & 0,658 & 0,002 & 2,031 & 0,011 & 100,299 \\
\hline CV (\%) & & 4,57 & 2,01 & 3,87 & 3,28 & 8,25 \\
\hline Nitrogênio (N) & 1 & $0,184^{N S}$ & $10,270^{* *}$ & $40,820^{* *}$ & $1,500^{* *}$ & $443.414,535^{\star *}$ \\
\hline $\mathrm{C} \times \mathrm{N}$ & 3 & 0,082 NS & $1,396^{\star \star}$ & $15,463^{\star *}$ & $4,500^{* *}$ & $114.389,935^{\star *}$ \\
\hline Resíduo & 8 & 0,071 & 0,096 & 2,403 & 0,000 & 61,592 \\
\hline CV (\%) & & 2,74 & 1,67 & 2,55 & 1,01 & 5,29 \\
\hline Média Geral & & 8,20 & 16,57 & 40,30 & 79,00 & $4.410,33$ \\
\hline
\end{tabular}

O comprimento da espiga foi diferente entre as cultivares avaliadas, sendo que a cultivar Sossego apresentou maiores valores $(8,87 \mathrm{~cm})$, diferindo das demais. As cultivares Sonic e Toruk, com comprimento de espiga de 8,23 e $8,08 \mathrm{~cm}$ respectivamente, apresentaram valores estatisticamente semelhantes entre si, porém superiores a cultivar Sintonia, a qual apresentou comprimento de espigas de $7,63 \mathrm{~cm}$ (Tabela 2). Estes resultados, já eram esperados, dado o fato que cada material genético possui uma demanda nutricional e um comportamento aos fatores climáticos diferentes, o que vários estudos como este já demonstraram. Teixeira Filho et al. (2007), por exemplo, ao avaliarem o efeito da irrigação por aspersão ao nitrogênio em cobertura sobre cultivares de trigo também observaram que o comprimento da espiga de trigo é diferente em função da cultivar implantada. Silva et al., (2015), também verificaram diferença no comprimento de espigas em diferentes cultivares de trigo. Ensaios com essa finalidade devem ser mantidos devido ao lançamento constante de materiais genéticos que requerem maior aferição em relação as suas especificidades.

Tabela 2. Dados médios de comprimento da espiga (CE) em função da cultivar de trigo estuada, Universidade Tecnológica Federal do Paraná UTFPR, 2019.

\begin{tabular}{cc}
\hline Cultivares & Comprimento da espiga $(\mathrm{cm})$ \\
\hline Sossego & $8,87 \mathrm{a}$ \\
Sonic & $8,23 \mathrm{~b}$ \\
Sintonia & $7,63 \mathrm{c}$ \\
Toruk & $8,08 \mathrm{~b}$ \\
\hline Média & 8,20
\end{tabular}

Médias seguidas de letras diferentes na coluna, diferem entre si pelo teste de Tukey a $5 \%$ de probabilidade
$\mathrm{Na}$ Tabela 3 são apresentadas as interações entre as cultivares e a forma de utilização do nitrogênio. Em relação à forma de aplicação de nitrogênio, observa-se que o número de espiguetas foi superior quando o nitrogênio é aplicado de forma parcelada para a maioria das cultivares (Sossego, Sonic e Sintonia). Resultado semelhante é observado para a variável número de grãos por espiga, no qual as cultivares Sossego e Sonic apresentaram maiores valores ao parcelar 0 nitrogênio em cobertura (Tabela 3).

Observa-se ainda na Tabela 3, que ao aplicar o nitrogênio em uma única dose, a cultivar Sintonia apresenta maiores valores de número de espiguetas por espiga $(16,86)$, diferenciando-se das demais. Entretanto, para o número de grãos por espigas, observa-se que apenas a cultivar Toruk, com valores médios 39,77 grãos por espigas, difere da cultivar Sonic (37,30 grãos por espigas), enquanto Sossego e Sintonia apresentam valores semelhantes, ao ser aplicado nitrogênio em uma única época.

O parcelamento da adubação nitrogenada aumenta a disponibilidade do nutriente no solo ( $\mathrm{Da}$ Ros et al., 2003). Neste sentido, supõem-se o parcelamento do nitrogênio no presente estudo, permitiu que o nutriente ficasse disponível por um período maior de tempo para as plantas, e assim, contribuiu para elevar o número de espiguetas por espigas e o número de grãos por espiguetas em algumas cultivares, não demonstrando mesmo comportamento para todas devidos suas diferenças de demanda nutricional. Teixeira Filho et al. (2007) relatam que o comprimento de espigas e o número de espiguetas por espiga, aumentaram significativamente com as doses de nitrogênio em trigo, respaldando a importância desse mineral para as gramíneas, onde sua maior absorção pela planta de trigo se concentra entre 0 alongamento e o espigamento, com concentração máxima na antese (Ecco et al., 2020). 
Tabela 3. Interação sobre o número de espiguetas, número de grãos por espiguetas, peso hectolitro e produtividade de cultivares de trigo e forma de aplicação do nitrogênio, Universidade Tecnológica Federal do Paraná - UTFPR, 2019.

\begin{tabular}{ccccc}
\hline Cultivares & \multicolumn{4}{c}{ Número de espiguetas } \\
\cline { 2 - 5 } Nitrogênio & Sossego & Sonic & Sintonia & Toruk \\
\hline Dose única & $15,53 \mathrm{Bb}$ & $15,77 \mathrm{Bb}$ & $16,86 \mathrm{Ab}$ & $15,50 \mathrm{Ba}$ \\
Parcelado & $17,90 \mathrm{Aa}$ & $17,47 \mathrm{Aa}$ & $17,93 \mathrm{Aa}$ & $15,60 \mathrm{Ba}$ \\
\hline Cultivares & \multicolumn{4}{c}{ Número de grãos por espigas } \\
Nitrogênio & Sossego & Sonic & Sintonia & Toruk \\
\hline Dose única & $39,50 \mathrm{ABb}$ & $37,30 \mathrm{Bb}$ & $39,40 \mathrm{ABa}$ & $39,77 \mathrm{Aa}$ \\
Parcelado & $46,77 \mathrm{Aa}$ & $39,50 \mathrm{Ba}$ & $40,00 \mathrm{Ba}$ & $40,13 \mathrm{Ba}$ \\
\hline Cultivares & \multicolumn{4}{c}{ Peso hectolitro $(\mathrm{pH})$} \\
Nitrogênio & Sossego & Sonic & Sintonia & Toruk \\
\hline Dose única & $80,00 \mathrm{Aa}$ & $77,00 \mathrm{Ba}$ & $80,00 \mathrm{Aa}$ & $80,00 \mathrm{Ab}$ \\
Parcelado & $77,00 \mathrm{Cb}$ & $77,00 \mathrm{Ca}$ & $80,00 \mathrm{Ba}$ & $81,00 \mathrm{Aa}$ \\
\hline Cultivares & & Produtividade $\left(\mathrm{kg} \mathrm{ha}{ }^{-1}\right)$ & \\
Nitrogênio & Sossego & Sonic & Sintonia & Toruk \\
\hline Dose única & $5.567,40 \mathrm{Aa}$ & $3.056,60 \mathrm{Da}$ & $4.349,00 \mathrm{Ca}$ & $5.212,40 \mathrm{Ba}$ \\
Parcelado & $5.536,40 \mathrm{Aa}$ & $2.908,00 \mathrm{Da}$ & $4.105,80 \mathrm{Cb}$ & $4.547,40 \mathrm{Bb}$ \\
\hline
\end{tabular}

Médias seguidas de letras maiúsculas na linha e minúsculas nas colunas diferentes, diferem pelo teste de Tukey a $5 \%$ de probabilidade.

A cultivar Toruk, apresenta $\mathrm{PH}$ superior quando o nitrogênio é parcelado (81), possivelmente porque para esse material genético teve uma maior síntese proteica, devido a disponibilidade de $\mathrm{N}$ mais próximo ao enchimento de grãos, estando disponível neste período e elevando a qualidade dos mesmos. Já a cultivar Sossego teve melhor $\mathrm{PH}$ quando o nitrogênio é aplicado em dose única (80). Ao fornecer o nitrogênio em uma única dose, Sonic apresenta o menor valor de $\mathrm{PH}$ entre as cultivares (77) e ao aplicar em parcelado, Sonic e Sossego apresentam os menores PH (Tabela 3).

$\mathrm{O} \mathrm{PH}$ é usado como medida tradicional de negociação do trigo em vários países e revela indiretamente a qualidade de grãos do cereal, sendo que quanto maior o seu valor, maior o valor comercial do produto (Costa et al., 2013). Destaca-se no presente estudo as cultivares Toruk e Sintonia, as quais apresentaram $\mathrm{PH}$ tipo $1 \mathrm{em}$ ambas as formas de utilização de nitrogênio, demonstrando que ambas adubações em cobertura são eficientes para a qualidade do trigo, podendo dar maior leque de possibilidade de adubação para essas cultivares.

Quanto a forma de utilização do N, a produtividade de grãos é menor para as cultivares Sintonia e Toruk ao parcelar o N, sem diferença para as demais cultivares. Observa-se diferença de produtividade de $665 \mathrm{~kg} \mathrm{ha}^{-1}$ entre o nitrogênio em dose única $\left(5.212,40 \mathrm{~kg} \mathrm{ha}^{-1}\right)$ e parcelado $(4.547,40$ $\mathrm{kg} \mathrm{ha}^{-1}$ ) para Toruk e de $244,20 \mathrm{~kg} \mathrm{ha}^{-1}$ para a cultivar Sintonia $\left(4.349,00\right.$ e $4.105,80 \mathrm{~kg} \mathrm{ha}^{-1}$, nitrogênio em dose única e parcelado, respectivamente) (Tabela 3). Em relação à produtividade de grãos, referente as cultivares avaliadas, observa-se que independente da forma de utilização do nitrogênio (dose única ou parcelado), as cultivar Sossego, Toruk, Sintonia e Sonic foram os genótipos que em ordem crescente, apresentaram as maiores produtividade respectivamente (Tabela 3).

Segundo Mikoanski (2017), o fornecimento do $\mathrm{N}$ em cobertura gera efeitos positivos no rendimento final e na qualidade dos grãos, ressaltando a necessidade do fornecimento deste nutriente para uma maior expressão do potencial produtivo dos materiais genéticos de trigo.

O parcelamento da adubação nitrogenada já é um segundo fator, onde pode vir a aumentar a disponibilidade de $\mathrm{N}$ no solo nos estádios de maior demanda deste nutriente pela cultura, porém não influenciar a produtividade do trigo, como visto por $\mathrm{Da}$ Ros et al. 2003. e que colabora com os dados observados para as cultivares Sossego e Sonic. Também Coelho et al., (1998), verificaram que o trigo se comportou de maneira indiferente, em relação ao parcelamento das doses de $\mathrm{N}$.

Já Costa et al., (2013) observaram que em certas cultivares, ocorre alterações nos componentes de rendimento e na produtividade em função da aplicação de nitrogênio, corroborando com os resultados do presente estudo para as cultivares (Toruk e Sintonia). Porém, os pesquisadores destacam que para a maioria dos genótipos de trigo é recomendado apenas uma aplicação de nitrogênio, sendo que esta apresenta melhores resultados quando realizada em perfilhamento ou emborrachamento, reduzindo assim o custo de uma aplicação adicional.

Outras investigações científicas também relatam que a produtividade é diferente, em função da adaptabilidade e da cultivar para a região em 
estudo (Silva et al., 2012; Espindula et al., 2010). Visto que o parcelamento do nitrogênio apresentou produtividade de grãos semelhante com os tratamentos que receberam o nutriente em dose única para Sossego e Sonic, e menor quando utilizado Toruk e Sintonia, a recomendação técnica indicada para o produtor seria realizar apenas uma aplicação de nitrogênio em dose única, reduzindo assim, custos operacionais com a cultura.

Observou-se na Tabela 3 que a cultivar Sossego apresentou produtividade de 2.511, $1.218 \mathrm{e}$ $355 \mathrm{~kg} \mathrm{ha}^{-1}$, a mais em relação as cultivares Sonic, Sintonia e Toruk, respectivamente, quando o nitrogênio é aplicado em dose única. Já com o parcelamento do nitrogênio, a cultivar expressou produtividade de 2.628 (Sonic), 1.431 (Sintonia) e 989 (Toruk) $\mathrm{kg} \mathrm{ha}^{-1}$ superior às demais.

Quanto a escolha do material a ser cultivado, resultados corroboram com Silva et al. (2012), os quais observaram que a adaptabilidade e a estabilidade produtiva das cultivares de trigo são variáveis em função do material utilizado, devido as diferentes demandas nutricionais e comportamento frente as condições ambientais e adaptabilidade regional que interferem fisiologicamente as plantas e logo a expressão do seu máximo potencial produtivo.

Apesar de existir variações nos componentes de rendimento e na produtividade da cultura do trigo em função da cultivar utilizada e do parcelamento ou não do nitrogênio, observa-se no presente estudo grande diferença de produtividade em função da cultivar avaliada, evidenciando que a escolha do genótipo de trigo a ser cultivado, é o fator que apresenta maior importância no cultivo deste cereal, seguido pela adubação nitrogenada em cobertura.

Em síntese, pode se afirmar que o comprimento da espiga é maior para a cultivar Sossego e menor para a cultivar Sintonia, e as cultivares Sonic, Sossego e Sintonia apresentam maior número de espiguetas por espiga, assim como a Sossego e Sonic maior número de grãos por espiga, quando o nitrogênio é aplicado parcelado.

$\mathrm{O} \mathrm{PH}$ do trigo foi maior na cultivar Toruk em relação as demais cultivares quando o nitrogênio é aplicado parcelado e Sonic apresenta menor $\mathrm{PH}$ entre as cultivares, com a adubação em dose única de nitrogênio.

Sintonia e Toruk apresentam maior produtividade quando o nitrogênio é aplicado em dose única, neste sentido, as cultivares, Sossego, seguida de Toruk, Sintonia e Sonic foram as cultivares que apresentaram maior produtividade respectivamente, independente da forma de aplicação de nitrogênio.

De modo geral, existe uma variabilidade genética em relação à produtividade $e$ ao comportamento das cultivares de trigo que vão sendo lançadas no mercado, portanto á resposta das mesmas em relação ao fornecimento de nitrogênio se torna variável e de difícil generalização, no entanto é certo que mesmo diante de tal variabilidade, o suprimento de $\mathrm{N}$ em cobertura, parcelado ou não, é essencial principalmente nos estádios que precedem o período de maior demanda nutricional da cultura, basicamente antes do enchimento de grãos, durante $o$ afilhamento e alongamento do colmo, acumulando $\mathrm{N}$ e tendo melhor taxa de crescimento e produtividade, além de boa qualidade dos grãos $(\mathrm{PH})$. Além disso, um solo suprido nutricionalmente e com condições climáticas favoráveis, sem restrição hídrica, é essencial para o melhor desempenho agronômico do trigo.

\section{REFERÊNCIAS}

Adam, A.L.F.; Alvarez, J.W.R. Fertilização nitrogenada em cobertura na cultura do trigo em Nueva Toledo, Paraguai. Revista Cultivando o Saber, 2015, 8, 4, 400-413.

Alvares, C. A.; Stape, J. L.; Sentelhas, P. C; Gonçalves, J. L.M.; Sparovek, G. Köppen's climate classification map for Brazil. Meteorologische Zeitschrift, 2013, 22, 6, 711-728.

Bhering, S. B.; Dos Santos, H. G.; Bognola, I. A.; Curcio, G.; Carvalho Junior, W. D.; ChagaS, C. D. S.; SilvA, J. D. S. Mapa de solos do Estado do Paraná, legenda atualizada. In: Embrapa Florestas-Artigo em anais de congresso (ALICE). In: CONGRESSO BRASILEIRO DE CIÊNCIA DO SOLO, 32., 2009, Fortaleza. O solo e a produção de bioenergia: perspectivas e desafios: anais. [Viçosa, MG]: SBCS; Fortaleza: UFC, 2009. 2008. Disponível em: <https://www.alice.cnptia.embrapa.br/bitstream/doc/ 578217/1/S-P5507.pdf>. Acesso em: out. de 2019.

Biotrigo Genética.; Cultivares. 2018. Disponível em: <http://biotrigo.com.br/cultivares/portf- olio> Acesso em: abr. de 2019.

Brasil. Ministério da Agricultura, do Abastecimento e da Reforma Agrária. Secretaria de Defesa Agropecuária. Regras para análise de sementes. Brasília: MAPA, 1992. 365p.

Camponogara, A. S.; Oliveira, G. A.; Georgin, J.; da Rosa, A. L. D. Avaliação dos Componentes de Rendimento do Trigo quando Submetido a Diferentes Fontes de Nitrogênio. Revista Eletrônica em Gestão, Educação e Tecnologia Ambiental, 2016, 20,1, 524532.

Coelho, M. A. O.; Souza, M. A.; Sediyama, T.; Ribeiro, A. C.; Sediyama, C. S. Resposta da produtividade de grãos e outras características agronômicas do trigo EMBRAPA-22 irrigado ao 
nitrogênio em cobertura. Revista Brasileira de Ciência do Solo, 1998, 22, 3, 555-561.

Conab. Companhia Nacional De Abastecimento. Boletim da Safra de Grãos. Boletim Grãos setembro $2018 . \quad$ Disponível em: <https://www.conab.gov.br/info-agro/safras/graos>. Acesso em: abr. de 2019.

Costa, L.; Zucareli, C.; Riede, C. R. Parcelamento da adubação nitrogenada no desempenho produtivo de genótipos de trigo. Revista Ciência Agronômica, 2013, 44, 2, 215-224.

Cruz, C. D. Genes Software - extended and integrated with the R, Matlab and Selegen. Acta Scientiarum, 2016, 38, 4, 547-552.

Cavalcante, J.A.; Rimieri, C.; Ribeiro, E.T.; Deluca, R.; Silva, W.G. Produtividade do trigo através de diferentes formas de adubação na semeadura e em cobertura. Revista cultivando o saber, Edição Especial, 2016, 1-14.

Da Ros, C. O.; Salet, R. L.; Porn, R. L.; Machado, J. N. C. Disponibilidade de nitrogênio e produtividade de milho e trigo com diferentes métodos de adubação nitrogenada no sistema plantio direto. Ciência Rural, 2003, 33, 5, 799-804.

Ecco, M.; Bedulli, D. L.; Lopes, A. B.; Richart, A.; Kieling, P. Adubação nitrogenada em cobertura em diferentes estádios fenológicos da cultura do trigo. Revista Brasileira De Agropecuária Sustentável, 2020, 10, 9-16.

Espindula, M. C.; Rocha, V. S.; Souza, M. D.; Grossi, J. A. S.; Souza, L. D. Doses e formas de aplicação de nitrogênio no desenvolvimento e produção da cultura do trigo. Ciência e Agrotecnologia, 2010, 34, 6, 14041411.

Fan, X.; Li, F.; Liu, F.; Kumar, D. Fertilization with a new type of coated urea: evaluation for nitrogen efficiency and yield in winter wheat. Journal of Plant Nutrition, 2004, 27, 5, 853-865.

lapar, Instituto Agronômico do Paraná. Médias históricas. 2018.2 Disponível em: $<$ http://www.iapar.br/pagina-1070.html >. Acesso em abr. de 2019.

Martins, I. S.; Cazetta, J. O.; Fukuda, A. J. F. Condições, modos de aplicação e doses de ureia revestida por polímeros na cultura do milho. Pesquisa Agropecuária Tropical, 2014, 44, 3, 271-279.

Mazzoncini, M.; Antichi, D.; Silvestri, N.; Ciantelli, G.; Sgherri, C. Organically vs conventionally grown winter wheat: Effects on grain yield, technological quality, and on phenolic composition and antioxidant properties of bran and refined flour. Food chemistry, 2015, 175, 445-451.

Mikoanski, Willian Miguel. Aplicação de fertilizante foliar na cultura do trigo associado ou não ao nitrogênio. 2017. Disponível em: 44<https://rd.uffs.edu.br/bitstream/prefix/810/1/MIKO ANSKI.PDF >. Acesso em: 22 de maio de 2020.

Orso, G.; Villetti, H.L.; Krenchinski, F.H.; Albrecht, A.J.P.; Albrecht, L.P.; Rodrigues, D.M.; Moraes, M.F. Comportamento da cultura do trigo sob efeito de fontes e doses de nitrogênio. Cerrado Agrociências, 2014, 5, 44-52.

Pottker, D.; Fabrício, A. C.; Nakayama, L. H. Doses e métodos de aplicação de nitrogênio para a cultura do trigo. Pesquisa Agropecuária Brasileira, 1984, 19, 10, 1197-1201.

Rando, A.M.; Zucareli, C.; Fronza, V.; Oliveira, F.Á.; Oliveira Júnior, A. Características produtivas do trigo em função de fontes e doses de nitrogênio. Pesquisa Agropecuária Tropical, 2013, 43, 1, 34-41.

Rodrigues, L. F.; Guimarães, V. F.; Silva, M. B. D.; Pinto Junior, A. S., Klein, J.; Da Costa, A. C. Características agronômicas do trigo em função de Azospirillum brasilense, ácidos húmicos e nitrogênio em casa de vegetação. Revista Brasileira de Engenharia Agrícola e Ambiental, 2014, 31-37.

Silva, R. R.; Benin, G.; Da Silva, G. O.; Marchioro, V. S.; De Almeida, J. L.; Matei, G. Adaptabilidade e estabilidade de cultivares de trigo em diferentes épocas de semeadura, no Paraná. Pesquisa Agropecuária Brasileira, 2012,46, 11,1439-1447.

Silva, J. D.; Arenhardt, E. G.; Krüger, C. A. M. B.; Lucchese, O. A.; Metz, M.; Marolli, A. A expressão dos componentes de produtividade do trigo pela classe tecnológica e aproveitamento do nitrogênio. Revista Brasileira de Engenharia Agrícola e Ambiental, 2015, 19, 1, 27-33.

Silva, S A.; Arf, O.; Buzetti, S.; Silva, M. G. D. Fontes e épocas de aplicação de nitrogênio em trigo em sistema plantio direto no Cerrado. Revista Brasileira de Ciência do Solo, 2008, 32, 2717-2722.

Teixeira Filho, M. C. M.; Buzetti, S.; Alvarez, R. D. C. F.; De Freitas, J. G.; Arf, O.; De Sá, M. E. Resposta de cultivares de trigo irrigados por aspersão ao nitrogênio em cobertura na região do Cerrado. Acta Scientiarum. Agronomy, 2007, 29, 3, 421-425.

Zagonel, J; Venancio, W. S.; Kunz, R. P.; Tanamati, $\mathrm{H}$. Doses de nitrogênio e densidades de plantas com e sem regulador de crescimento afetando o trigo, Cultivar OR-1. Ciência Rural, 2002, 32, 1, 25-29. 